\title{
Driving Torque Model and Accuracy Test of Multilink High-Speed Punch
}

\author{
Fuxing Li, ${ }^{1}$ Hao Liu, ${ }^{1}$ Menglei Li, ${ }^{1}$ Jun Guo, ${ }^{1}$ Xinjian Lu, ${ }^{2}$ Jianhui Zhou, ${ }^{3}$ \\ Maohua Xiao (D), ${ }^{1}$ and Weihua Wei ${ }^{4}$ \\ ${ }^{1}$ College of Engineering, Nanjing Agricultural University, Nanjing 210031, China \\ ${ }^{2}$ School of Mechanical Engineering, Nanjing Institute of Technology, Nanjing 211167, China \\ ${ }^{3}$ Ship Research and Design Center of China, Wuhan 430064, China \\ ${ }^{4}$ College of Mechanical and Electronic Engineering, Nanjing Forestry University, Nanjing 210037, China
}

Correspondence should be addressed to Maohua Xiao; xiaomaohua@njau.edu.cn

Received 23 December 2017; Revised 12 March 2018; Accepted 3 April 2018; Published 13 May 2018

Academic Editor: Anna Vila

Copyright (c) 2018 Fuxing Li et al. This is an open access article distributed under the Creative Commons Attribution License, which permits unrestricted use, distribution, and reproduction in any medium, provided the original work is properly cited.

\begin{abstract}
Inertia force is an important factor for operation stability and stamping precision of high-speed punch; adjusting drive torque of high-speed punch can realize effective control of inertia force. In this paper, a kind of $600 \mathrm{KN}$ multilink high-speed punch inertia force balancing mechanism was designed. The calculation model of ideal inertia force was proposed based on conservation of energy and numerical analysis method. In addition, the calculation model of ideal driving torque were analyzed, simplified, and corrected by using numerical calculation and simulation methods, which solved the problem of controlling inertia force from the perspective of driving torque and realized the stability strategy planning of high-speed multilink punch press. Finally, the proposed ideal driving torque calculation model was simulated and verified by ADAMAS and bottom-dead-point accuracy test was carried out.
\end{abstract}

\section{Introduction}

The precision punching press is an essential equipment in precision blanking process, and it is the key and basic premise for the realization of the fine blanking technology and fine blanking compound process. High-speed precision punch has been used rapidly in Europe, North America, Japan, and other developed countries. More well-known brands include German SMG-Feintool, Britain's Fine-O-Matic, Switzerland's Schmid, Fenitool, Heinrich, Japan's kawasaki, and Mori Iron Works [1]. In recent years, with the rapid development of China's electronics, communications, computers, household appliances, and automotive industry, the demand for fine blanking parts has also increased rapidly, especially focusing on the high quality and efficient production of fine blanking parts [2-4]. The dynamic balance of punch has aroused the greatest concern, and the balance performance and inertia force are the key factors affecting the efficiency of high-speed precision punch. Unbalanced or excessive inertial force will make high-speed punch vibrate and the connecting screw fracture and even cause the surrounding buildings to vibrate $[5,6]$.

High-speed precision press usually adopts crank-slider mechanism, and previous studies have investigated the balance of this mechanism. According to the five kinds of inertial force balancing mechanism' characteristics, Zhao et al. made it clear that pneumatic balancing device should not be used in high-speed press [7]. In common balancing devices, linkage balancer and counterweight disk can reduce the inertial force of high-speed mechanical presses. By comparing the design examples of Stephenson-III six-bar linkage press, the linkage balancer and the counterweight disks are suitable for dealing with shaking force and shaking moment, respectively [8].

Too large inertial force will inevitably result in lower bottom dead center (BDC) accuracy, the system stability will also deteriorate. Xiao et al. used Monte Carlo method to simulate the position of BDC under different speeds and measure the BDC position with no load. The experimental results verify the feasibility of this method [9]. In addition, D'Alembert equation and deformation compatibility analysis 


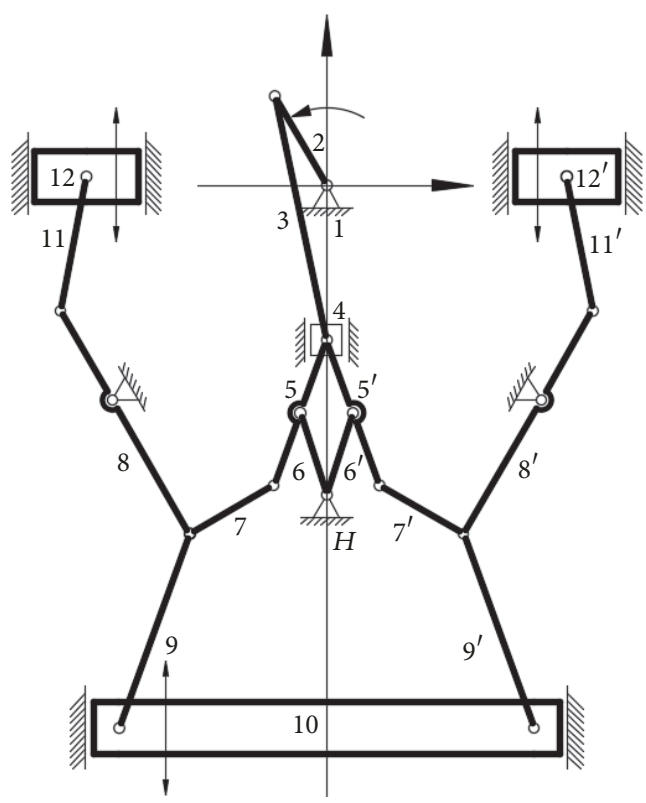

FIGURE 1: Diagram of a drive mechanism.

simulate hybrid cam linkage in Pro/Mechanism; the input motion characteristics designed with Bezier curves [10-12] and so forth are all used in the design of pressure balance.

Vibration is inevitable in press work; Li et al. proposed a comprehensive optimization of plane vibration force balance method: for given dimensions and driving characteristics of a mechanism, the inertial force depends only on the mass distribution of the moving links [13]. A three-degreeof-freedom mathematical vibration model of a high-speed punching press was established in order to predict the motion state under different working conditions, as well as the influence of load fluctuation on motor speed [14]. These two methods can effectively solve the flutter generated in the press work.

As it can be seen from the above analysis, there are a variety of dynamic balance optimization methods [15], and the press in this paper is the counterdirection configuration of the vice-slider balance [16, 17]. This paper derives the ideal torque calculation model and obtains the analysis and optimization of the calculation model through numerical calculation and simulation. In order to verify the working stability of the mechanism used in the paper, two schemes were used to test the precision of the bottom dead center of the press. Finally, a specific control scheme of inertial force is proposed.

\section{Inertia Force Balancing Mechanism of Multilink High-Speed Punch Press}

The punching machine investigated in this paper is based on an improved mechanism of multilink high-speed precision press with a stamping force of $600 \mathrm{KN}$. In addition to driving link, the punch press is symmetrical, the horizontal inertia forces cancel each other out, and only the vertical balance force needs to be optimized. Therefore, a connecting rod balance slider mechanism is added on the end of toggle link of the press, extends toggle link 8 , and adds connecting link 11 and slider 12 . Slider 12 can move in the vertical direction with the drive of the connecting rod (Figure 1); the new balance scheme can effectively utilize the structural space of the press.

The balance of inertial forces requires verification of the mechanism by numerical analysis and simulation; after reoptimization of the ideal driving torque calculation model, the accurate geometrical parameters of the bar and the balance slider are analyzed, and then the ideal optimization scheme is designed.

\section{Ideal Driving Torque Calculation Model of Multilink High-Speed Punch Press}

Aiming at the multilink high-speed precision press, the ideal driving torque formula is rederived and the inertia force is considered.

In the quasistatic conversion conditions, ignoring the inertia, friction, and elastic deformation, the ideal driving torque for multilink presses is calculated as follows:

$$
M_{k p}^{\alpha}=F s_{\alpha}^{\prime}
$$

In the formula, $M_{k p}^{\alpha}$ represents the nominal torque $(\mathrm{Nm})$, $F$ represents the nominal force $(\mathrm{KN})$, and $s_{\alpha}^{\prime}$ represents the speed of the slider simulation $(\mathrm{mm} / \mathrm{rad})$.

In the absence of friction, the calculation model of ideal driving torque is proposed. First of all, there is the following formula:

$$
M d \varphi=F d s+d(E+V)
$$




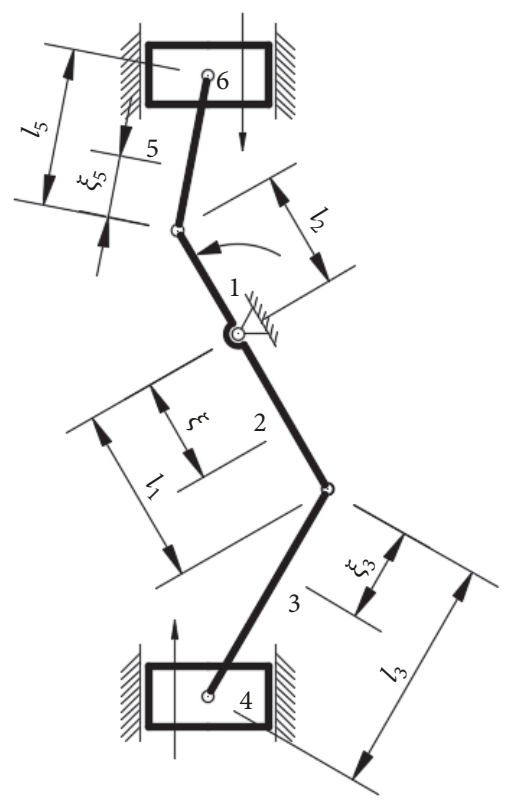

FIGURE 2: Diagram of a high-speed slider-crank mechanism (with balancing mechanism).

After the derivation of the time variable,

$$
M=F s_{\alpha}^{\prime}+\sum_{i=1}^{N}\left(m_{i} K_{1 i} \omega^{2}+J_{c i} K_{2 i} \omega^{2}+m_{i} g \alpha_{\alpha i}^{\prime}\right)
$$

In the formula, $K_{1 i}=v_{i} / \omega \cdot a_{i} / \omega^{2}=s_{\alpha i}^{\prime} \cdot a_{\alpha i}^{\prime}, K_{2 i}=\omega_{i} / \omega$. $\alpha_{i} / \omega^{2}=\omega_{\alpha i}^{\prime} \cdot \alpha_{\alpha i}^{\prime}$

Among them, $M$ is the ideal driving torque, $F$ is the nominal force, $d \varphi$ is the instantaneous angle of the crank, $d s$ is the instantaneous displacement of the slider, $E$ is the kinetic energy of the system, and $V$ is the potential energy of the system. $K_{1 i}, K_{2 i}$ are the coefficients related to the rod group structure and the crank angle; $s_{\alpha i}^{\prime}$ is defined as the velocity simulation of the $i$ th bar, $a_{\alpha i}^{\prime}$ is defined as the acceleration simulation of the $i$ th bar. $\omega_{\alpha i}^{\prime}$ is defined as the angular velocity simulation of the $i$ th bar and $\alpha_{\alpha i}^{\prime}$ is defined as the angular acceleration simulation of the $i$ th bar.

According to the dynamic system balance characteristics of large high-speed precision press and the crank-slider mechanism, the main and auxiliary slider moving parts meet the following relations:

$$
\begin{aligned}
& m_{1} \omega^{2} r_{1}\left(\cos \omega t+\varepsilon_{1} \cos 2 \omega t\right) \\
& =m_{2} \omega^{2} r_{2}\left(\cos \omega t+\varepsilon_{2} \cos 2 \omega t\right) .
\end{aligned}
$$

To achieve a good balance effect, order $\varepsilon_{1}=\varepsilon_{2}$, then

$$
m_{1} r_{1}=m_{2} r_{2} \text {. }
$$

Because of the smaller stroke of the slider of the highspeed precision press (most are within $50 \mathrm{~mm}$ ), the movement direction of the main and auxiliary slider is opposite, so the influence of potential energy can be ignored. Formula (3) is further simplified as follows:

$$
M \approx F s_{\alpha}^{\prime}+m^{\prime} K_{1} \omega^{2} .
$$

In the formula, $m^{\prime}$ is the equivalent mass of the upper die mass and the translational mass containing the moving parts of the main and subsliders; $K_{1}$ is determined by the product of the velocity simulation and the acceleration simulation of the slider.

\section{Design of Ideal Driving Torque}

Figure 2 shows that high-speed crank-slider mechanism with the dynamic balancing mechanism and the calculation parameters are taken from the $600 \mathrm{KN}$ closed two-point high-speed precision press. The design parameters are as follows: stroke is $30 \mathrm{~mm}$, nominal pressure stroke is $1.6 \mathrm{~mm}$, and number of strokes is between $200 \mathrm{spm}$ and $600 \mathrm{spm}$; parameters of rod system parts are shown in Table 1.

4.1. Optimization of Computational Model. The press operates at 600 SPM. The comparison between the ideal driving torque and the theoretical value calculated according to formula (6) as shown in Figure 3. In addition, the maximum torque is required to overcome the inertia force by formula (6) being $1102.3 \mathrm{~N} \cdot \mathrm{m}$, and corresponding crank angle is 45 degrees (the theoretical value is $1498.1 \mathrm{~N} \cdot \mathrm{m}$ and the corresponding crank angle is 45 degrees), and the minimum value is $-1102.3 \mathrm{~N} \cdot \mathrm{m}$, the corresponding crank angle is 321 degrees (the theoretical value is $-1498.1 \mathrm{~N} \cdot \mathrm{m}$ and the corresponding crank angle is 321 degrees), and the maximum torque is required to overcome the stamping force is $2897.9 \mathrm{~N} \cdot \mathrm{m}$ (the theoretical value is $2613.4 \mathrm{~N} \cdot \mathrm{m}$ ), respectively, $73.6 \%$ and $110.9 \%$ of the theoretical values. The error is large, and the formula needs to be corrected.

The revised formula is as follows:

$$
M \approx F s_{\alpha}^{\prime}+1.35 m^{\prime} K_{1} \omega^{2} .
$$


TABLE 1: Parameters of parts.

\begin{tabular}{lccccc}
\hline & Crank 2 & Connecting rod 3 & Slider 4 & Auxiliary connecting rod 5 & Auxiliary slider 6 \\
\hline Quality/kg & 210 & 110 & 1200 & 55 & 720 \\
Connecting rod length $/ \mathrm{mm}$ & $l_{1}=15$ & 350 & - & 177 & - \\
Barycenter coordinates $\xi_{\mathrm{i}} / \mathrm{mm}$ & $l_{2}=25$ & 72 & - & 33.0 & - \\
$\begin{array}{l}\text { Moment of inertia } \\
J_{i \mathrm{C}} /\left(\times 10^{5} \mathrm{~kg} \cdot \mathrm{mm}^{2}\right)\end{array}$ & -1.2 & 32.0 & - & & - \\
\hline
\end{tabular}

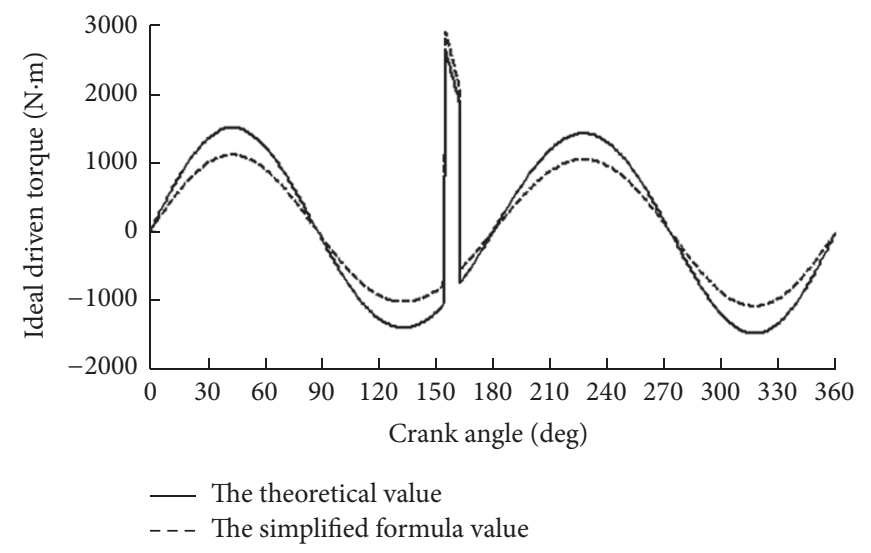

FIGURE 3: Comparison of the value calculated with simplified formula and the theoretical value.

The ideal driving torque calculated according to (7) is compared with the theoretical value as shown in Figure 4. Consequently, the calculated values tend to be consistent.

When the crank speed changes from $300 \mathrm{spm}$ to $800 \mathrm{spm}$, Table 2 shows that the comparison of inertia force is calculated by correction formula and stamping torque maximum. Error between value calculated by correction formula and theoretical value is minimal.

From the derivation analysis of formulas (6) to (7), the formula for the calculation of ideal driven torque can be summed up as follows:

$$
M \approx \lambda_{1} F s_{\alpha}^{\prime}+\lambda_{2} m^{\prime} K_{1} \omega^{2} .
$$

In the equation, $\lambda_{1}$ is the dimensionless coefficient associated with the pressure torque. As for high-speed multilink press in this paper; this coefficient is a function of speed. $\lambda_{2}$ is a fixed value that the dimensionless coefficient is related to the torque of the inertia force. As for high-speed multilink press in this paper, the coefficient is 1.53 .

4.2. Adams Simulation and Verification. The torque simulation results shown in Figure 5 match the simulation results considering the effect of gravity. The maximum torque required to overcome the inertia force is $2373.6 \mathrm{~N} \cdot \mathrm{m}$, which is $99.4 \%$ of the theoretical value of $387.9 \mathrm{~N} \cdot \mathrm{m}$. The corresponding crank angle is 31 degrees. The torque needed to overcome the pressure is $1669.4 \mathrm{~N} \cdot \mathrm{m}$, which is $99.3 \%$ of the theoretical value of $1681.2 \mathrm{~N} \cdot \mathrm{m}$. The simulation value makes an agreement with the theoretical value.
Taking slider 12 as an example, the minimum value of the maximum inertia force and RMS (root mean square) value of inertia force were selected as the objective function, respectively. The quality of slider 12 is optimized for optimization variables in Adams.

Figures 6 and 7 show the optimization results. In Figure 6, the RMS value of inertial force is $32.3 \%$ the previous optimization, and the maximum value of inertial force occurs at the upper dead center, which decreases $69.5 \%$ compared with that of the previous optimization. At the bottom dead center, the minimum value is $16.4 \%$ less than that of the optimization. In Figure 7, the minimum value of the maximum inertia force is $29.1 \%$ before the previous optimization. The maximum of the inertia force at the top dead center, which is $73.1 \%$ less than that of the previous optimization. At the bottom dead center, the minimum value is $31.5 \%$ less than that of the previous optimization.

The optimization results showed that the optimization objective is to minimize the RMS of inertial force and minimize the maximum of inertial force. Consequently, the final optimization results are better.

\subsection{The Influence of the Crank Radius on the Driving Torque}

4.3.1. The Impact of Key Positions. In this paper, several key positions of the modified press are analyzed. The position of the fixed end of the bar 6 in the rhombus mechanism is adjusted in the vertical direction $\left(y_{H}\right)$ and the fixed hinge of the rod 8 is adjusted in the horizontal direction $\left(x_{18}\right)$. Figures 8 and 9 show the ideal driving torque curve of different crank radius. 
TABLE 2: Comparison of the maximum torque with different speeds.

\begin{tabular}{|c|c|c|c|c|c|c|}
\hline Crank rolling velocity/spm & 300 & 400 & 500 & 600 & 700 & 800 \\
\hline \multicolumn{7}{|c|}{$\begin{array}{l}\text { The maximum torque of overcoming } \\
\text { the inertia force/Nm. }\end{array}$} \\
\hline Calculated value & 375.1 & 664.9 & 1041.3 & 1496.9 & 2038.1 & 2662.7 \\
\hline Theoretical value & 375.1 & 664.9 & 1041.3 & 1496.9 & 2038.1 & 2662.7 \\
\hline Error & $0.0 \%$ & $0.0 \%$ & $0.0 \%$ & $0.0 \%$ & $0.0 \%$ & $0.0 \%$ \\
\hline \multicolumn{7}{|c|}{$\begin{array}{l}\text { Maximum torque of overcoming } \\
\text { punching pressure/Nm. }\end{array}$} \\
\hline Calculated value & 3396.3 & 3195.9 & 2937.1 & 2621.9 & 2246.2 & 1949.9 \\
\hline Theoretical value & 3396.2 & 3195.3 & 2934.4 & 2618.4 & 2241.4 & 1956.4 \\
\hline Error & $0.0 \%$ & $0.0 \%$ & $0.1 \%$ & $0.1 \%$ & $0.2 \%$ & $-0.3 \%$ \\
\hline
\end{tabular}

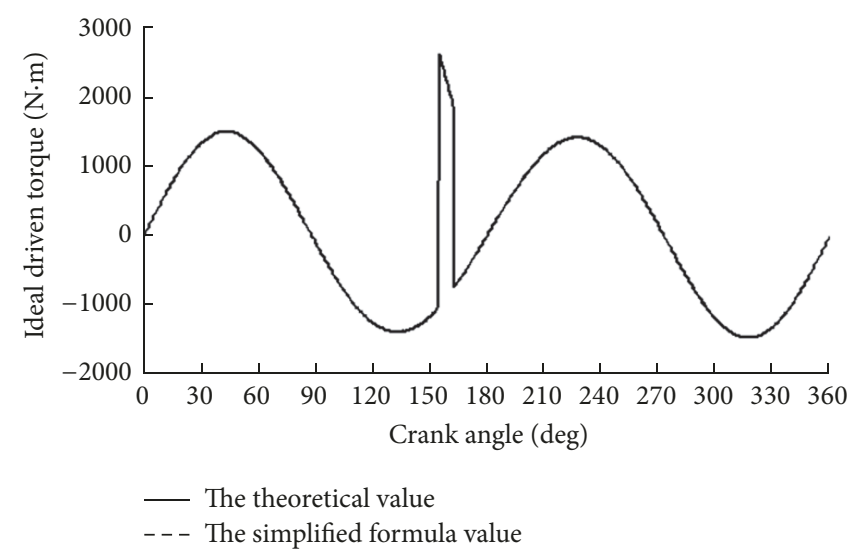

FIGURE 4: Comparison of the value calculated with correction formula and the theoretical value.

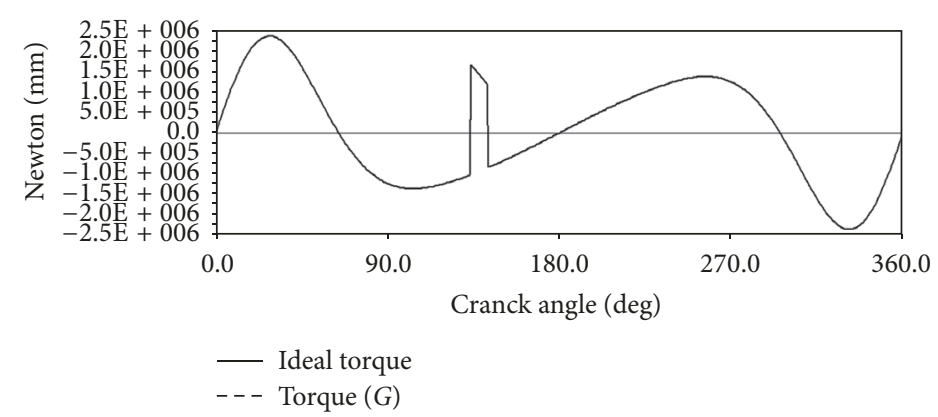

FIgURE 5: Torque curves.

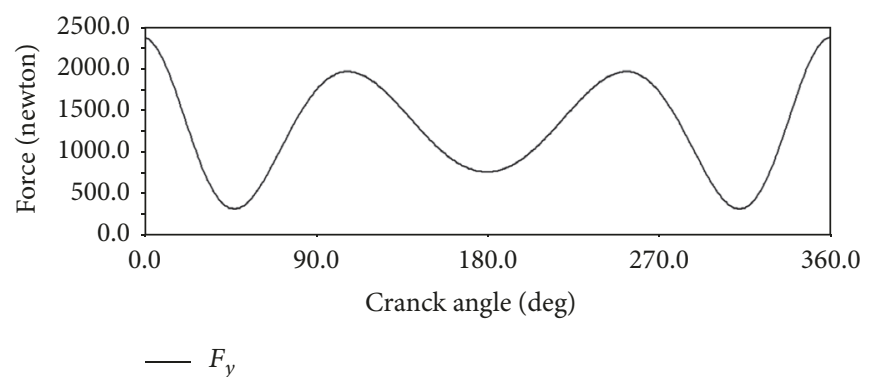

FIGURE 6: The vertical inertial force exerted on crown by toggle 8 (optimized). 


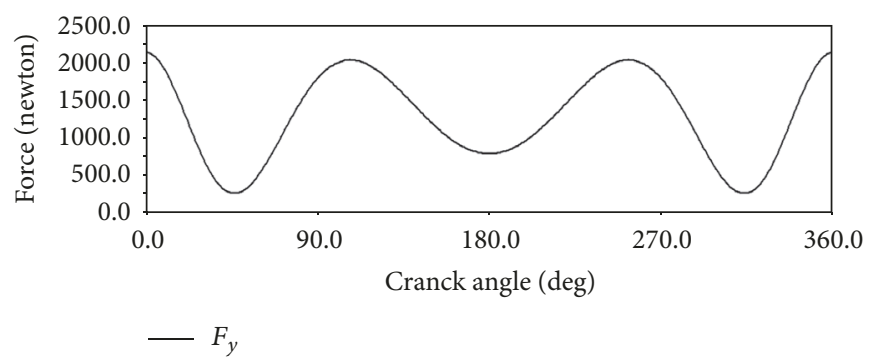

FIGURE 7: The vertical inertial force exerted on crown by toggle 8 (optimized).

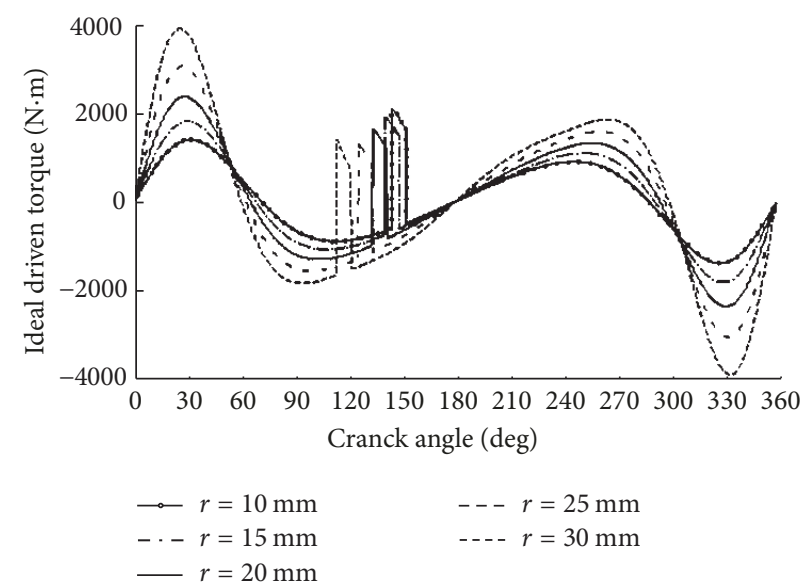

FIGURE 8: Relationship between torque and $y_{H}$ position.

From the data of Table 3 obtained by adjusting the position of $y_{H}$, the change in crank radius has a significant effect on the torque required to overcome the inertia force and stamping force, also the angle of nominal force stroke.

Obviously, decreasing the crank radius is very beneficial to reduce the torque required to overcome inertia force and enlarging the crank radius helps reduce the torque required to overcome stamping force and make the stamping prolonged. Similarly, the lateral force of the slider will also reduce due to the decrease of the angle between the connecting rod 9 and the vertical direction.

From the data of Table 4 obtained by adjusting the position of $x_{18}$, the change in crank radius has little effect on the torque required to overcome the inertia force and stamping force and the angle of nominal force stroke.

Therefore, increasing the crank radius properly is beneficial to reduce the torque required to overcome the inertia force. Increasing the crank radius helps to extend the stamping time, while the torque required for stamping force increases firstly and then decreases. Overall, the adjustment of $x_{18}$ position has little effect on torque.

4.3.2. The Impact of the Key Rod Length. According to (8), the equivalent mass $m^{\prime}$ can be reduced to decrease the torque required to overcome inertial forces in high-speed precision presses. On the one hand, rely on the rational design slider structure to reduce the slider quality; on the other hand, use slider made by light ally. Reasonable choice of rod parameters can reduce the value of $K_{1}$, decreasing the torque required to overcome inertial forces. For crank presses with certain slider stroke, the only parameter that can influence the value of $K_{1}$ is the link length.

The method that reduced the value of $K_{1}$ can decrease the ideal driving torque required to overcome inertial force. Under the premise of certain slider stroke, respectively, adjust $\operatorname{rod} l_{2}, l_{3}, l_{6}, l_{7}$ rod length and the ideal driving torque curve for different crank radius is shown in Figure 10.

According to Figure 10, when changing the length of $l_{2}$, $l_{3}, l_{6}, l_{7}$ to ensure the slider stroke, the torque required for stamping reduces and stamping time will increase with crank radius increasing; reducing the crank radius can decrease the torque required to overcome the inertia force. The angle of nominal force stroke decreases with the increase of the crank radius; thus the lateral pressure on the slider will reduce. The ideal crank torque limit is required to overcome the inertia force corresponding basically to the crank angle.

\section{Dynamic Precision Test}

The dynamic precision test was carried out on the same machine tool in order to verify the accuracy of the press designed according to the ideal driving torque. The model is $\mathrm{Xu}$ Duan JL75G-60, and the measuring device is shown in Figure 11. There are two test programs as follows.

Warming and Constant Speed. Run at a constant speed for 3 hours from the initial state at different operating speeds. 


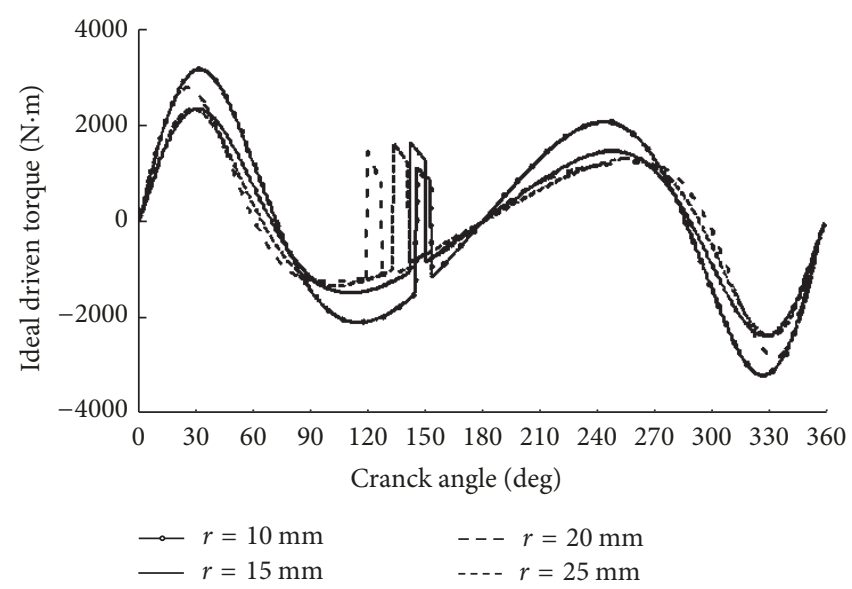

Figure 9: Relationship between torque and $x_{18}$ position.

TABLE 3: The influence of the change of the crank radius.

\begin{tabular}{|c|c|c|c|c|c|}
\hline & \multicolumn{5}{|c|}{ Crank radius/mm } \\
\hline & 10 & 15 & 20 & 25 & 30 \\
\hline $\begin{array}{l}\text { The torque of overcoming the } \\
\text { inertia force } / \mathrm{N} \cdot \mathrm{m} \text {. }\end{array}$ & 1411.3 & 1832.9 & 2395.4 & 3096.3 & 3952.7 \\
\hline $\begin{array}{l}\text { The torque of overcoming the } \\
\text { stamping force } / \mathrm{N} \cdot \mathrm{m} \text {. }\end{array}$ & 2115.4 & 1943.5 & 1675.2 & 1311.7 & 1091.1 \\
\hline $\begin{array}{l}\text { The angle of nominal force } \\
{\text { stroke }{ }^{\circ}}^{\circ}\end{array}$ & 145 & 141 & 134 & 126 & 114 \\
\hline
\end{tabular}

TABLE 4: The influence of the change of the crank radius.

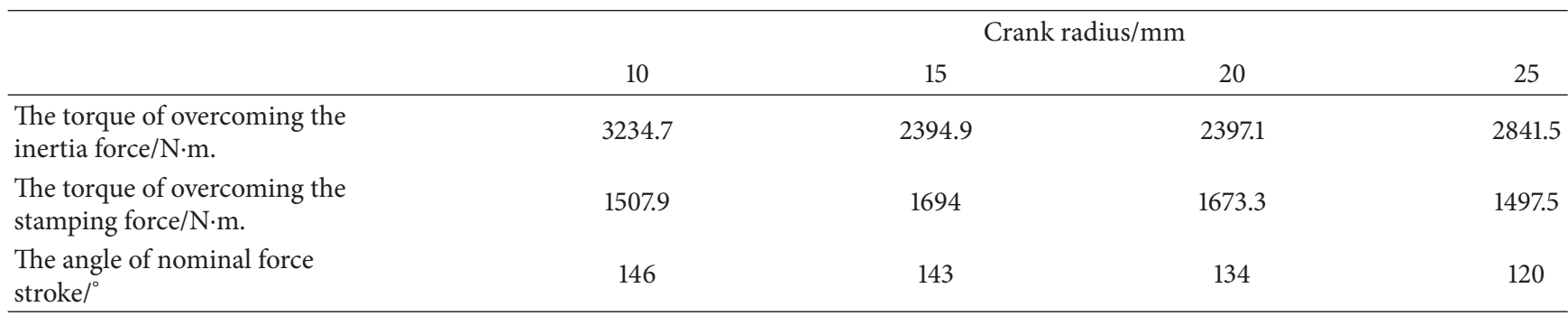

Operating speeds are $200 \mathrm{spm}, 250 \mathrm{spm}$, and $300 \mathrm{spm}$, respectively. Change the test speed; the downtime is no less than $10 \mathrm{~h}$.

Constant Temperature and Speed as Follows. After test "Warming and Constant Speed," if BDC no longer continue to offset, that is, the machine reaches a state of thermal equilibrium, continuous measurement of time is more than $0.5 \mathrm{~h}$.

In Figure 12, the chart data is measured by the "Warming and Constant Speed" method. From the data results, BDC condition of the press machine at different speeds is as follows: the deviation of BDC gradually increases and gradually stabilizes with the passage of time; the cumulative deviation is about $0.1 \mathrm{~mm}$, within the error range. This indicates that the dynamic precision of BDC of the prototype meets the design requirements.

The three groups of experiments shown in Figure 13 are conducted to verify the stability of the press at constant temperature and constant speed. Average BDC deviations at different speeds were $0.59 \mu \mathrm{m}, 0.73 \mu \mathrm{m}$, and $1.13 \mu \mathrm{m}$, respectively. Standard deviations were $1.65 \mu \mathrm{m}, 3.14 \mu \mathrm{m}$, and $6.15 \mu \mathrm{m}$, respectively. As shown in Figure 13, the bottom dead center deviation fluctuates around the test reference; the machine tool has reached a thermal equilibrium condition and still keeps good bottom dead center accuracy and stability under long-term operating conditions.

Experiments show that the punch for improved driving torque has a good bottom dead center accuracy and operational stability, which can be used as a practical press manufacturing.

\section{Conclusion}

In this paper, the inertial force balance mechanism of multilink high-speed punching machine is proposed based on the principle of energy conservation and numerical analysis; 


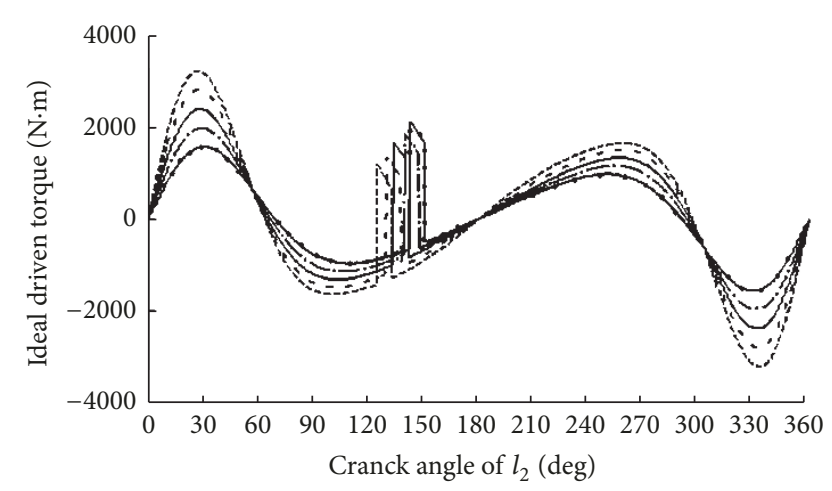

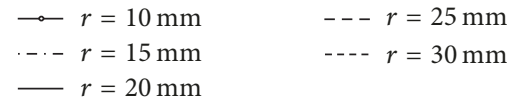

(a) $\operatorname{Rod} l_{2}$

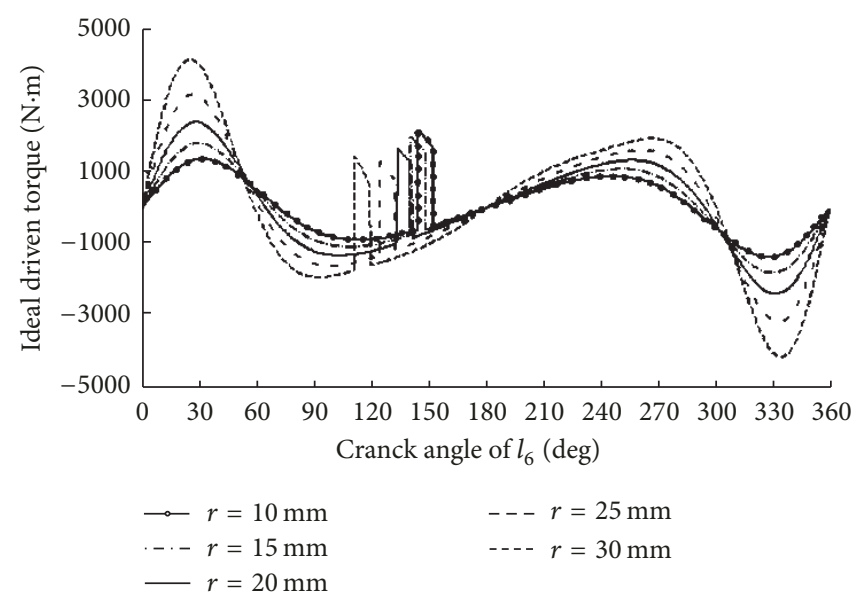

(c) $\operatorname{Rod} l_{6}$

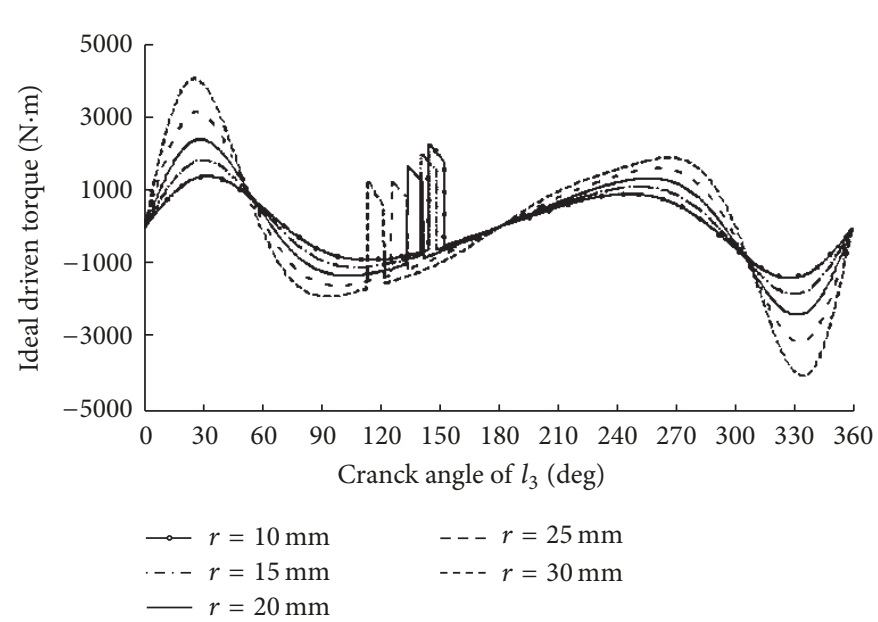

(b) $\operatorname{Rod} l_{3}$

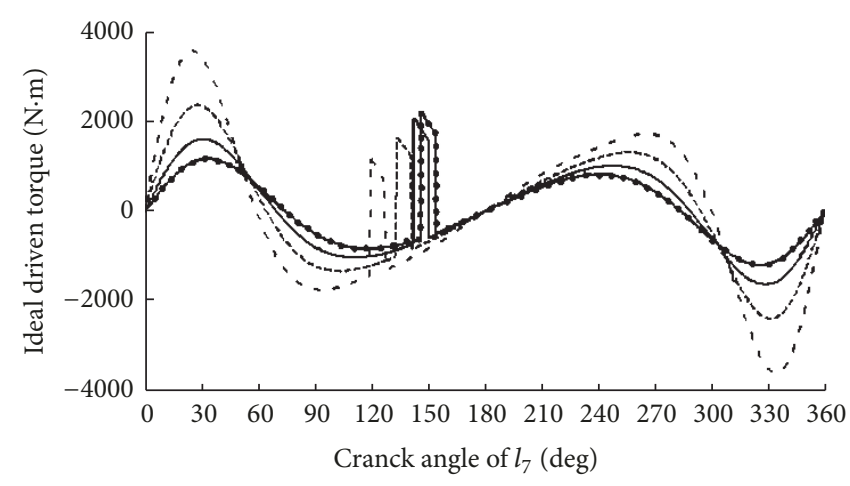

(d) $\operatorname{Rod} l_{7}$

FIgURE 10: The ideal driving torque curves with the same stroke and different crank radius.

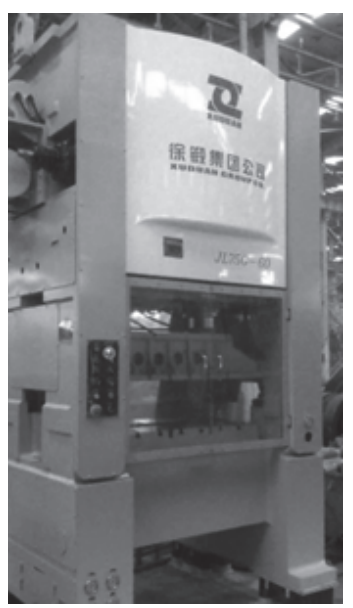

(a) $600 \mathrm{kN}$ multilink highspeed precision press

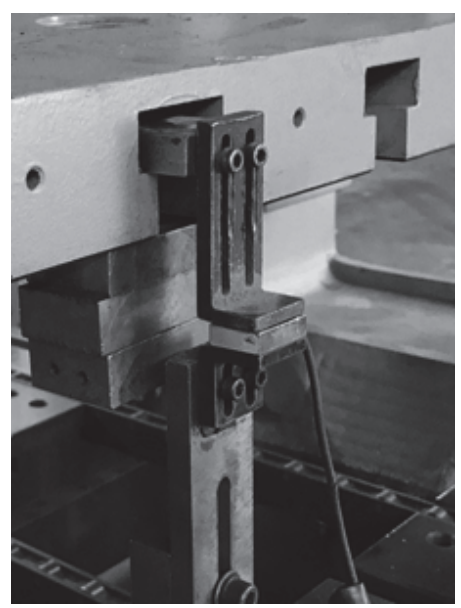

(b) Sensor arrangement

FIGURE 11: Experimental machine tool and equipment. 


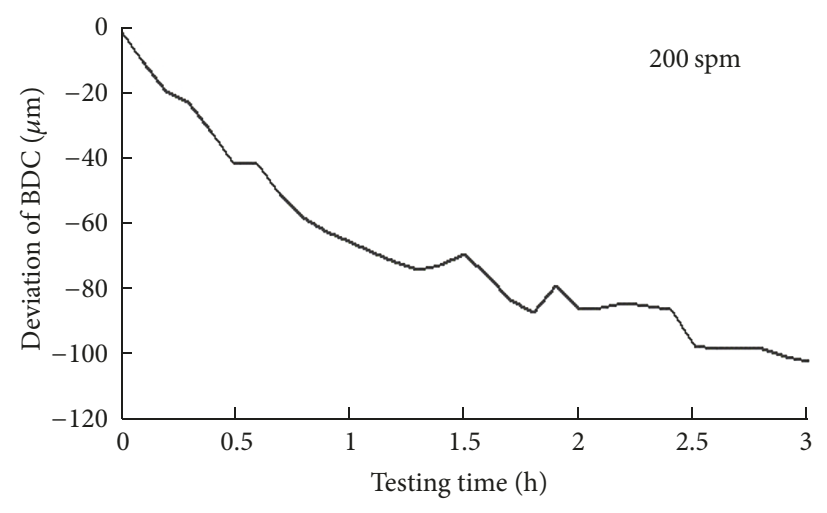

(a) The BDC deviation at $200 \mathrm{spm}$

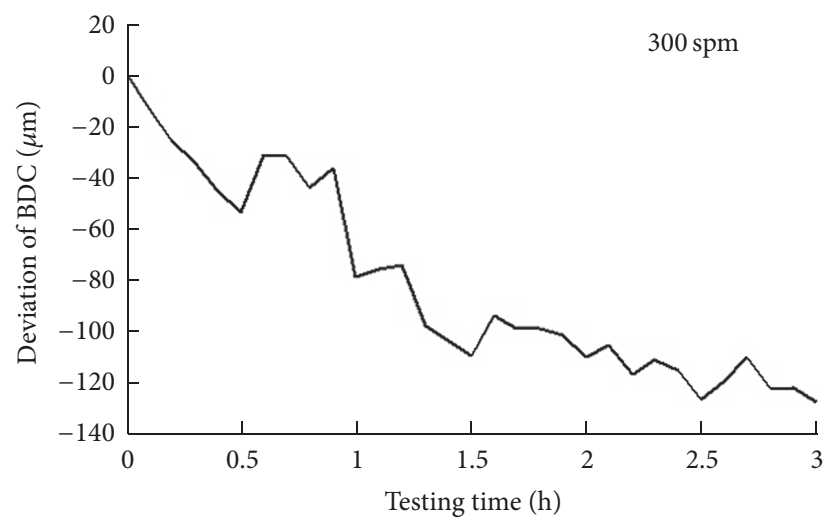

(c) The BDC deviation at $300 \mathrm{spm}$

FIgURE 12: The BDC deviation within 3 hours at different speeds.

$300 \mathrm{spm}$

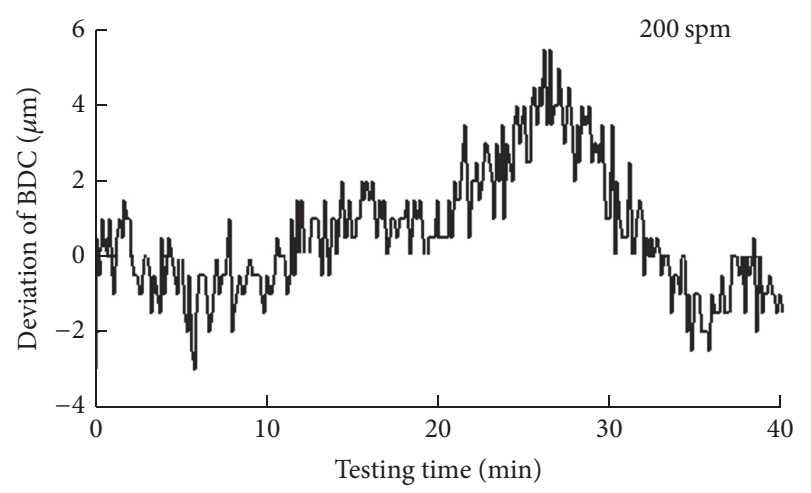

(a) The BDC deviation within 40 minutes

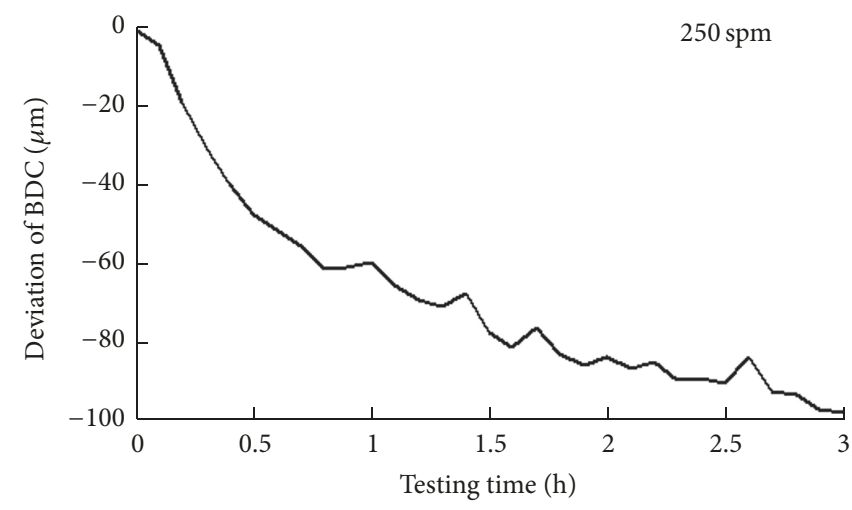

(b) The BDC deviation at $250 \mathrm{spm}$

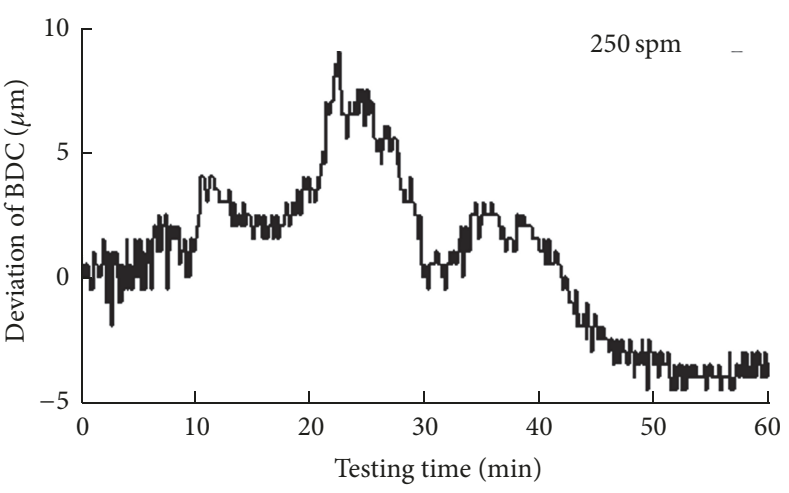

(b) The BDC deviation within 60 minutes

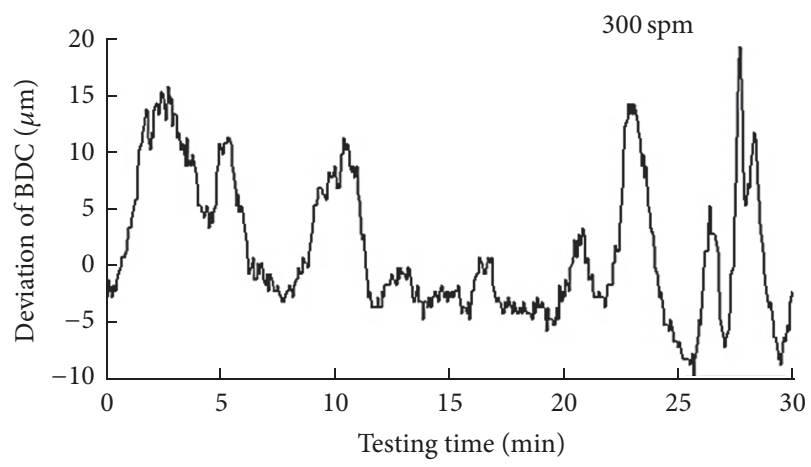

(c) The BDC deviation within 30 minutes

FIGURE 13: BDC accuracy at constant temperature and speed. 
the calculation model of ideal driving torque is deduced, optimized, and verified by Adams simulation.

(1) The ideal driving torque calculation model of multilink high-speed precision press can be expressed as follows: the sum of required torque to overcome inertia and the product. This product is one of the nominal forces and the velocity simulation of the slider. The torque required to overcome the force of inertia is the product of the equivalent mass, $K_{1}$, and the squared angular velocity of the crank.

(2) The coefficients $\lambda_{1}$ and $\lambda_{2}$ are, respectively, added to the two models that constitute the ideal driving torque calculation model, in which $\lambda_{1}$ reflects the sensitivity of the stamping torque to the rotating speed. For the high-speed multilink press studied, the coefficient is a function of speed. $\lambda_{2}$ is the dimensionless coefficient related to the moment of inertia and is a fixed value.

(3) For the mechanism proposed in this paper, the vertical position of the $H$ point in the rhombus mechanism can be properly adjusted, and the same is true for fixed hinge horizontal position of rod 8 and changing the lever length to reduce the crank radius, thereby reducing the ideal drive torque required overcoming the inertia force. For other multilink high-speed precision press, a similar approach can reduce the ideal drive torque in order to overcome inertial forces.

(4) The experimental results show that the improvement of the driving torque of the multilink press is necessary.

\section{Conflicts of Interest}

The authors declare that there are no conflicts of interest regarding the publication of this paper.

\section{Acknowledgments}

The research is funded partially by the National Key Research and Development Program of China (2016YFD0701103), Science and Technology Foundation of Outstanding Young Talents of Nanjing Agricultural University (YQ201605), the Fundamental Research Funds for the Central Universities Fund (KYZ201760), and Program for Student Innovation through Research and Training of Nanjing Agricultural University (1730A32).

\section{References}

[1] M. Deng, G. M. Hu, L. Lin, and Z. F. Liu, "Present situation and development trend of fine blanking press," Forging \& Stamping Technology, vol. 8, no. 41, pp. 1-6, 2016.

[2] L. Z. Xiang and C. Q. Wang, "Wang, Control System Design of Fine-blanking Machines Based on PLC, China Measurement \& Test, vol. 39, no. 2, pp. 98-101, 2013.

[3] S. D. Zhao, X. L. Zhang, C. Y. Gao, and et al., "The present situation and development trend of high speed press," Forging Equipment \& Manufacturing Technology, vol. 40, no. 1, pp. 1725, 2005.

[4] Q. X. Xia, X. T. Hu, D. Chen et al., "Current research and development tendency of fine blanking technology," Forging \& Stamping Technology, vol. 40, no. 7, pp. 1-7, 2015.
[5] Y. Chen, Y. Sun, and D. Yang, "Investigations on the dynamic characteristics of a planar slider-crank mechanism for a highspeed press system that considers joint clearance," Journal of Mechanical Science and Technology, vol. 31, no. 1, pp. 75-85, 2017.

[6] J. Bai, Z. Yu, S. Tong, and D. Zheng, "Optimal design for partial inertia force cancellation in ultra high speed pressing machine," Advanced Materials Research, vol. 291-294, pp. 1909-1916, 2011.

[7] S. D. Zhao, X. L. Zhang, C. Y. Gao, W. Liu, and Y. Zhang, "Investigation on inertial force balance assembly units and their dynamic characteristics of a high speed press," China Metal Forming Equipment \& Manufacturing Technology, vol. 5, pp. 1419, 2005.

[8] C.-H. Li and P.-L. Tso, "The study of dynamic balancing for high-speed presses," JSME International Journal Series C Mechanical Systems, Machine Elements and Manufacturing, vol. 49, no. 3, pp. 657-662, 2007.

[9] M. Xiao, G. Geng, G. Li, H. Li, and R. Ma, "Analysis on dynamic precision reliability of high-speed precision press based on Monte Carlo method," Nonlinear Dynamics, vol. 90, no. 4, pp. 2979-2988, 2017.

[10] Y. Li, Y. Sun, B. Peng, and F. Hu, "Dynamic modeling of a highspeed over-constrained press machine," Journal of Mechanical Science and Technology, vol. 30, no. 7, pp. 3051-3059, 2016.

[11] Z. Ge, W. Ma, K. Zhang, and W. Huang, "Mechanism design and dynamic analysis of hybrid cam-linkage mechanical press," Key Engineering Materials, vol. 474-476, pp. 803-806, 2011.

[12] H. S. Yan and R.-C. Soong, "Kinematic and dynamic design of four-bar linkages by links counterweighing with variable input speed," Mechanism and Machine Theory, vol. 36, no. 9, pp. 10511071, 2001.

[13] Y. J. Li, Y. Sun, F. F. Hu, and S. H. Wang, "Research on comprehensive dynamic balance optimization of high speed press," Journal of Huazhong University of Science and Technology (Natural Science Edition), vol. 44, no. 6, pp. 24-28, 2016.

[14] T. Xu, Q. Xia, X. Long, and G. Buffa, "Vibration Control of a High-Speed Precision Servo Numerically Controlled Punching Press: Multidomain Simulation and Experiments," Shock and Vibration, vol. 2017, Article ID 4593546, 17 pages, 2017.

[15] W. H. Wei, Y. T. Lia, X. B. Long, and C. T. Mei, "The research progress of machining mechanisms in milling wood-based materials," Bioresources, vol. 13, no. 1, pp. 2139-2149, 2017.

[16] X. Xu, Y. Jiang, and H. P. Lee, "Multi-objective optimal design of sandwich panels using a genetic algorithm," Engineering Optimization, vol. 49, no. 10, pp. 1665-1684, 2017.

[17] X.-M. Xu, Y.-P. Jiang, H.-P. Lee, and N. Chen, "Sound insulation performance optimization of lightweight sandwich panels," Journal of Vibroengineering, vol. 18, no. 4, pp. 2574-2586, 2016. 


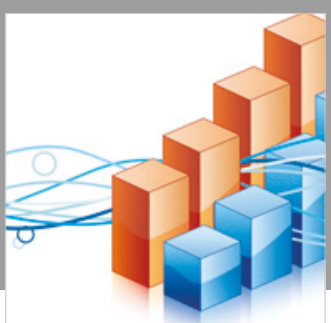

Advances in

Operations Research

\section{-n-m}
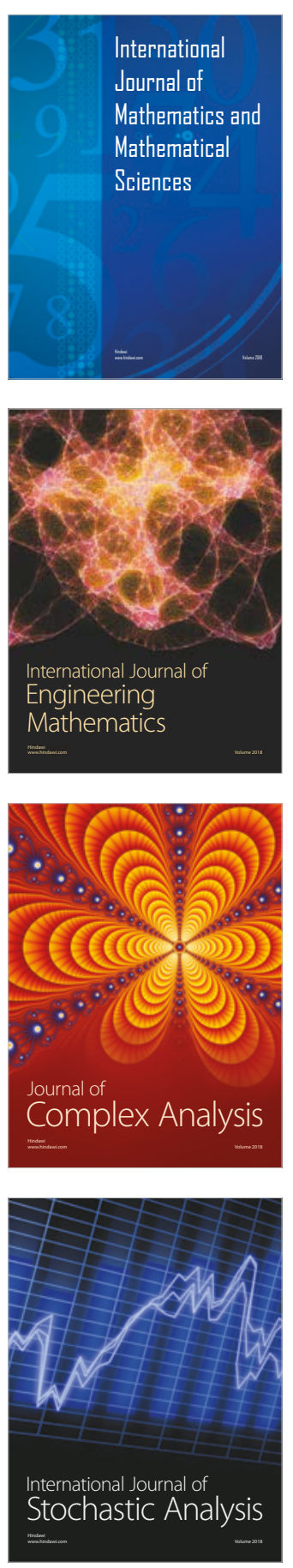
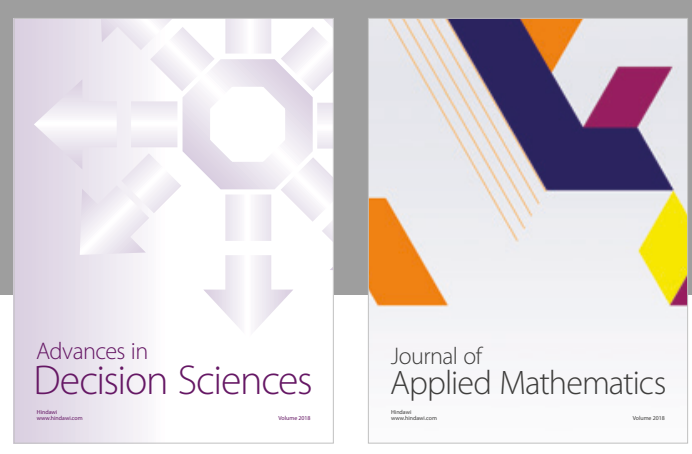

Journal of

Applied Mathematics
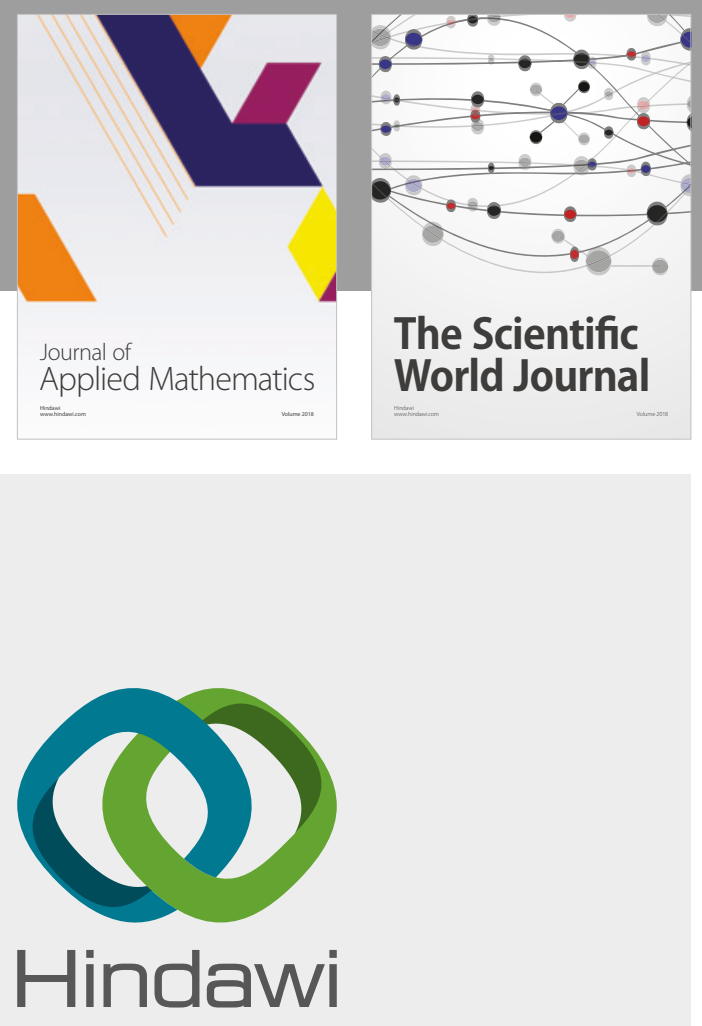

Submit your manuscripts at

www.hindawi.com

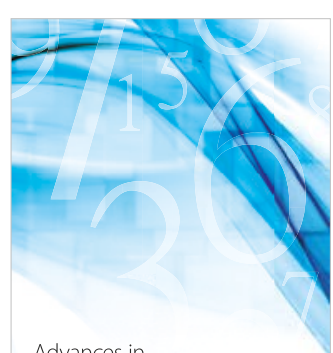

Advances in
Numerical Analysis
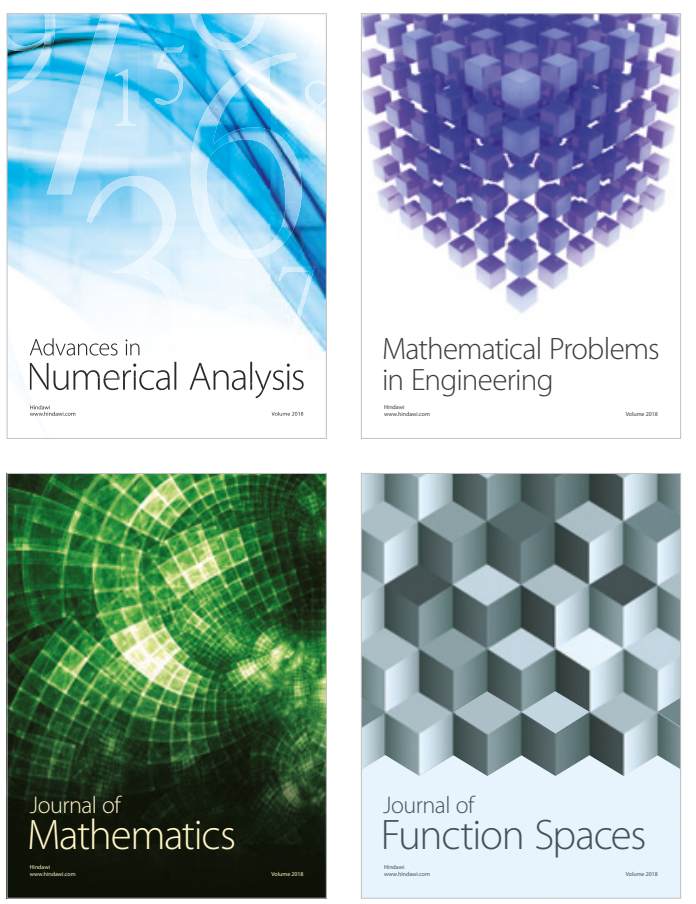

Mathematical Problems in Engineering

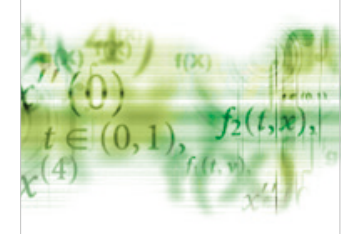

International Journal of

Differential Equations

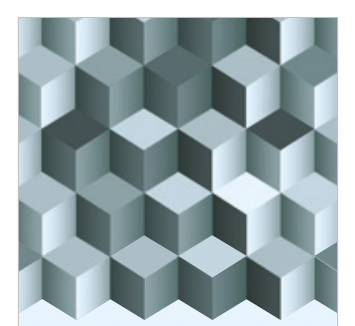

Journal of

Function Spaces

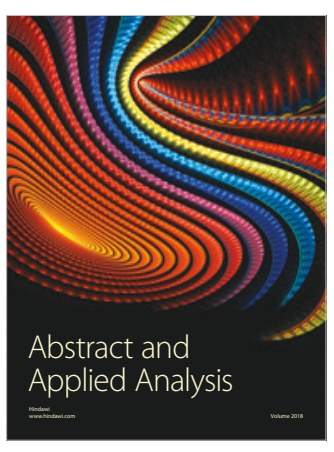

The Scientific

World Journal

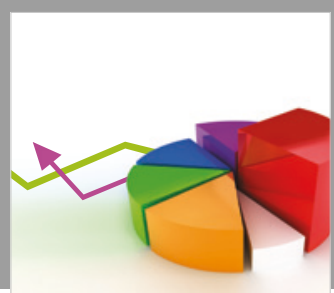

Journal of

Probability and Statistics
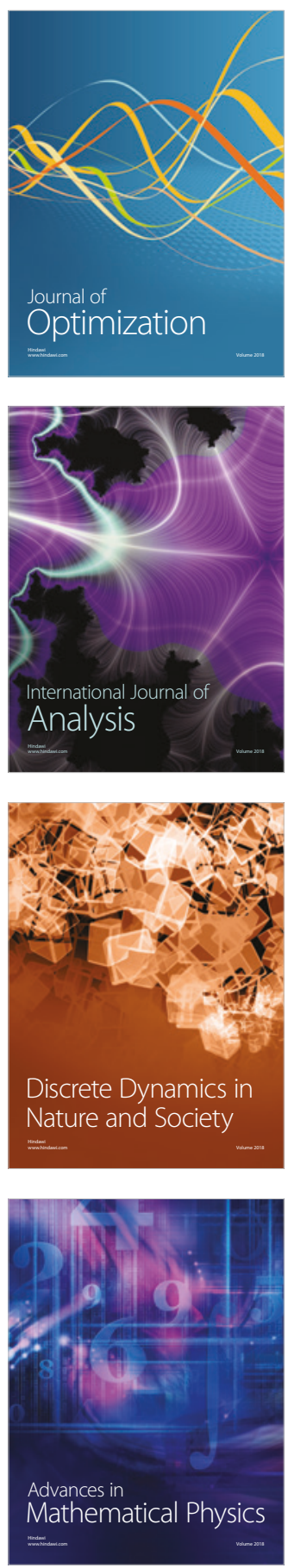